\title{
GATA2 mutation in long stand Mycobacterium kansasii infection, myelodysplasia and MonoMAC syndrome: a case-report
}

\author{
Daniela Palheiro Mendes-de-Almeida ${ }^{1,2}$, Francianne Gomes Andrade², Gustavo Borges ${ }^{3}$, \\ Filipe V. dos Santos-Bueno ${ }^{2}$, Iracema F. Vieira ${ }^{4}$, Luana Kelly M. da S. da Rocha ${ }^{5}$, Daniella A. Mendes-da-Cruz ${ }^{6,7}$, \\ Rosely M. Zancopé-Oliveira ${ }^{8}$, Rodrigo T. Calado ${ }^{3}$ and Maria S. Pombo-de-Oliveira ${ }^{2^{*}}$ (D)
}

\begin{abstract}
Background: GATA2 is a transcription factor that is a critical regulator of gene expression in hematopoietic cells. GATA2 deficiency presents with multi-lineage cytopenia, mycobacterial, fungal and viral infections. Patients with GATA2 mutation have a high risk of developing myelodysplastic syndrome or acute myeloid leukemia.

Case presentation: We described a 43 years-old white male with 20-year follow-up of autoimmune and thrombotic phenomena, hypothyroidism, disseminated refractory Mycobacterium kansasii infection and MonoMAC syndrome. GATA2 c.1061 C> T; p.T354 M mutation was identified after he progressed from myelodysplastic pancytopenia to refractory anemia with excess blasts type II. His relatives were also investigated and he underwent unsuccessful haematopoietic stem cell transplantation. We discuss the clinical features, genetic diagnosis and treatment of this immunodeficiency disorder.
\end{abstract}

Conclusions: This case illustrates the challenge how a multidisciplinary disease should be handle. Once usual causes of immunodeficiency were excluded, clinicians should considerGATA2 deficiency in patients with myelodysplasia and long-standing Mycobacterium kansasii infection.

Keywords: GATA-2 mutation, MonoMAC syndrome, Myelodysplastic syndrome, Myelodysplasia, Mycobacterium kansasii

\section{Background}

Disseminated non-tuberculosis mycobacterium (NTM) infections are found in subjects with advanced human immunodeficiency virus infection, hairy cell leukaemia, or under immunosuppressive therapy regimes [1]. Host immune deficiencies with genetic disorders of the interleukin-12 (IL-12)-interferon- $\gamma$ (IFN- $\gamma$ ) pathway has been also associated with NTM [1]. GATA2 autosomal gene mutations are among these genetic disorders that confer predisposition NTM infections [1]. GATA2 encodes

\footnotetext{
* Correspondence: mpombo@inca.gov.br

${ }^{2}$ Pediatric Hematology-Oncology Program, 6thfloor, Research Center,

Instituto Nacional de Câncer-INCa, Rua André Cavalcanti, 37, Rio de Janeiro

Zip code: 20231- 050, Brazil

Full list of author information is available at the end of the article
}

an ill-defined protein containing two zinc-finger domains that is located in the $3 \mathrm{p} 21.3$ region and is a key transcriptional regulator of haematopoiesis, lymphopoiesis, and vascular development [2]. Germline loss-of-function mutations in the GATA2 gene are associated with myelodysplastic syndrome (MDS), acute myeloid leukaemia (AML) and opportunistic infections, including NTM infections [3]. GATA2 deficiency/ haploinsufficiency is an etiologic in Emberger and MonoMAC syndromes [4]. Emberger syndrome includes primary lymphedema, congenital sensorineural deafness, and cutaneous or anogenital warts [5]. MonoMAC syndrome is characterized by monocytopenia, predisposition to NTM infections, typically of the Mycobacterium avium complex, viral and fungal infections, pulmonary alveolar

(c) The Author(s). 2019 Open Access This article is distributed under the terms of the Creative Commons Attribution 4.0 International License (http://creativecommons.org/licenses/by/4.0/), which permits unrestricted use, distribution, and reproduction in any medium, provided you give appropriate credit to the original author(s) and the source, provide a link to the Creative Commons license, and indicate if changes were made. The Creative Commons Public Domain Dedication waiver (http://creativecommons.org/publicdomain/zero/1.0/) applies to the data made available in this article, unless otherwise stated. 
proteinosis, and natural killer (NK) and B cell deficiencies [6]. Recognition of an underlying immune defect associated with genetic susceptibility is crucial for rational treatment, preventive care, and family screening. Our aim is to describe a 20-year follow-up of a male patient finally diagnosed with MonoMAC syndrome. He had long-stand cytopenia, autoimmune and thrombotic phenomena, hypothyroidism and disseminated refractory Mycobacterium kansasii infection. He received anti-NTM regimen with different drugs for seven years. GATA2 mutation was identified in the patient, and his relatives were also investigated. We discuss the clinical features, genetic diagnosis and treatment of this challenging immunodeficiency disorder.

\section{Case presentation}

A 43-year-old white male was seen in our clinic due to recurrent sinusitis, ankle and knee arthritis, painless nodular skin lesions at extremities, and eosinophilia in 2008. His clinical history is marked by long-standing pancytopenia and MDS diagnosed in 1996 at age 30, when he complained of spontaneous rectal bleeding and fatigue, which was diagnosed as haemorrhoidal disease (Fig. 1). Six years after the MDS diagnosis, he was admitted to the hospital with hepatosplenomegaly, erythema nodosum, retroperitoneal lymph node enlargement, and bilateral pleural effusion. Laboratory investigations failed to demonstrate any fungal, bacterial, or HIV infection. Chronic granulomatous pleuritis was discovered, and he was treated empirically for tuberculosis with standard doses of isoniazid, rifampicin, and pyrazinamide. Allergy to pyrazinamide developed, and ethambutol was used instead. Circulating blood cells demonstrated pancytopenia with low monocytes (haemoglobin, 7,7 g/dL; white blood cell (WBC) 3000 cells $/ \mu \mathrm{L}$; lymphocytes, $750 / \mu \mathrm{L}$; monocytes, $60 / \mu \mathrm{L}$; and platelets, $95,000 / \mu \mathrm{L})$. One year later, monocytopenia improved slightly, but thrombocytopenia worsened (WBC, 1900 cells $/ \mu \mathrm{L}$; lymphocytes $475 / \mu \mathrm{L}$; monocytes, $114 / \mu \mathrm{L}$; and platelets, $33,000 / \mu \mathrm{L})$. Seven years later (2006), developed respiratory distress and bronchial analysis was negative for bacterial infection. $\mathrm{He}$ was then treated with clarithromycin for possible atypical pneumonia. In 2007, a $27 \%$ decrease in total body weight loss was observed. The patient had been complaining of night fever, night sweats, Raynaud phenomenon, left thigh superficial thrombophlebitis, and painless perimalleolar ulcers. Skin and bone marrow (BM) biopsies were performed. The ulcer biopsy revealed vasculitis with eosinophils, whereas the BM biopsy showed myelodysplastic features and noncaseating granuloma, and myeloculture was negative. In 2008, he developed hypothyroidism, recurrent sinusitis, ankle and knee swellings and nodular skin lesions (Fig. 1). Antineutrophil cytoplasmic antibodies and antinuclear antibodies were within normal limits. He presented WBC $28,610 / \mu \mathrm{L}$ with marked eosinophilia $(5440 / \mu \mathrm{L}) \cdot \mathrm{BM}$ aspirate and biopsy diagnosed MDS without excess blasts. Churg-Strauss syndrome was suspected, and after 3 months of prednisone

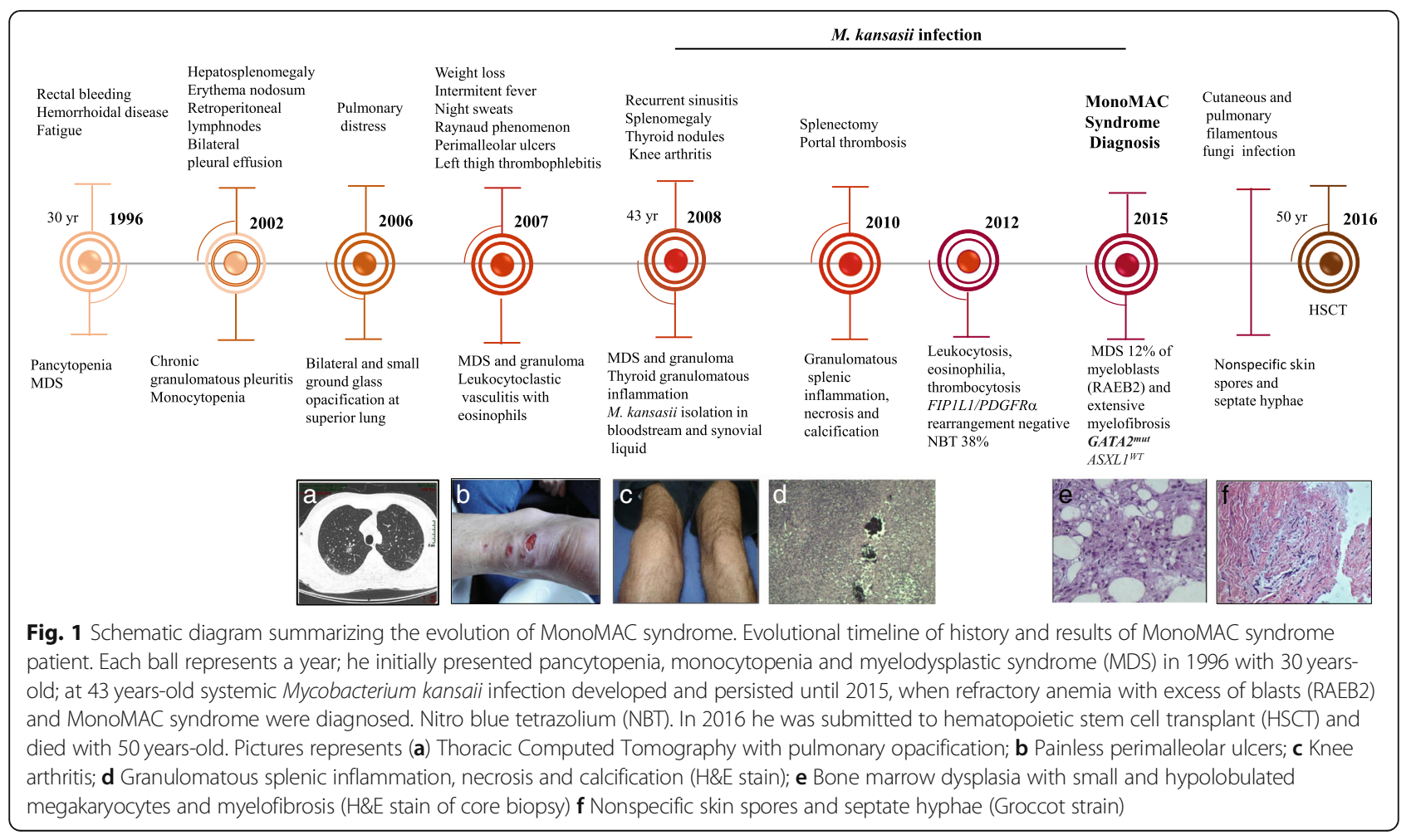


(50 mg/day), he developed arthritis and sustained night fevers. Blood culture, arthrocentesis and thyroid biopsy were performed. Mycobacterium kansasii, a slow-growing mycobacterium, was identified in the bloodstream and synovial fluid. The thyroid histopathological analysis demonstrated chronic and acute granulomatous inflammation. Rifampicin, isoniazid and ethambutol were restarted in addition to clarithromycin for the next 2 years. Progressive spleen enlargement culminated in splenectomy in 2010. Portal thrombosis developed at the immediate post-operatory period, and oral anticoagulant was administered. The histopathology features displayed granulomatous splenic inflammation, abscesses and central necrosis. In 2012, an increased WBC $(39,080 / \mu \mathrm{L})$ with eosinophilia $(20,630 / \mu \mathrm{L})$ and thrombocytosis $(1,099,000 / \mu \mathrm{L})$ were found. The nitro blue tetrazolium test, which is useful in diagnosing chronic granulomatous diseases, suggested a defect in phagocytosis, as it was positive in $38 \%$ of cells, and FIP1L1/PDGFRa rearrangement was negative, excluding hypereosinophilic syndrome. He received hydroxyurea, dexamethasone and anti-NTM therapy containing moxifloxacin until 2015, when MDS refractory anaemia with excess blasts (12\%) type II (RAEB II) was diagnosed. The entire GATA2 exons were investigated and a heterozygous germline GATA2 (c.1061 C> T; p.T354M) mutation was determined by Sanger sequencing of peripheral blood leukocytes (as in Additional file 1: Table S1). The combination of results led to a final diagnosis of MonoMAC syndrome. The patient was treated with 3 days of idarubicin and 7 days of cytarabine chemotherapy and developed cutaneous and pulmonary filamentous fungal infection. A skin biopsy was performed and identified nonspecific spore and septate hyphae. He was treated with liposomal B amphotericin and voriconazole, received consolidation chemotherapy with high doses of cytarabine and was submitted to haematopoietic stem cell transplant (HSCT) with a myeloablative conditioning regimen from his HLA- identical brother. He died nine months after transplantation in October 2016, in other institution, so we are not sure of the exactly cause of death. GATA2 gene sequencing (exon 5) was performed on his relatives, including his HSCT donor and was positive only in his two healthy sons, aged 21 and 28- year-old (Figs. 2 and 3). The hotspot regions for acquired mutations exons 11-12 of ASXL1 sequencing were also performed in the three GATA2 mutant $\left(\right.$ GATA2 ${ }^{\text {mut }}$ ) subjects but were ASXL1 Wild-Type $\left(A S X L 1^{\mathrm{WT}}\right)$ as in Additional file 1: Table S1.

\section{Discussion and conclusions}

MonoMAC syndrome was first described in 2010 in a group of 18 adult patients with disseminated NTM and other opportunistic infections [6]. Half of the patients were diagnosed with MDS/AML, characterized by reduced numbers of circulating monocytes, B cell, and NK cells [6]. Since then, patients with persistent cytopenia, even in the absence of diagnostic morphologic dysplasia, are suspected of having MonoMAC syndrome. In 2011, the MonoMAC syndrome was linked to 12 distinct GATA2 mutations, including the T354 M in the second zinc-finger domain that was also found in our patient [5]. Although GATA2 mutations might be found in a large number of sporadic cases, disease phenotype follows an autosomal dominant inheritance pattern [5]. To date, nearly 380 GATA2-deficient patients have been reported, with an estimated prevalence of myeloid neoplasia of at least 75\% [7]. The most frequent clinical features described in GATA2 deficient patients according to literature reviews and in our patient are summarized in Table 1. Non-infectious conditions also have been described in MonoMAC cases, especially endocrine, rheumatologic,

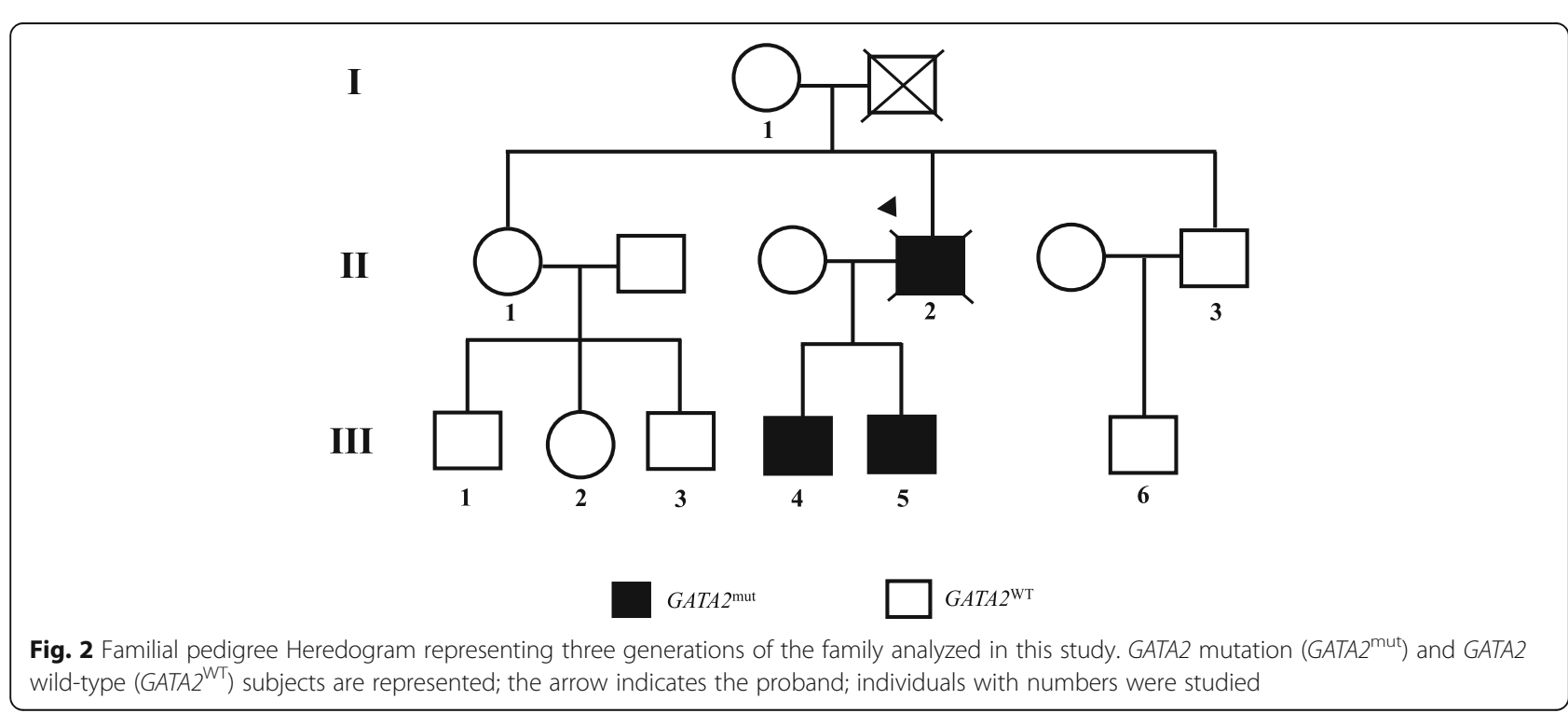




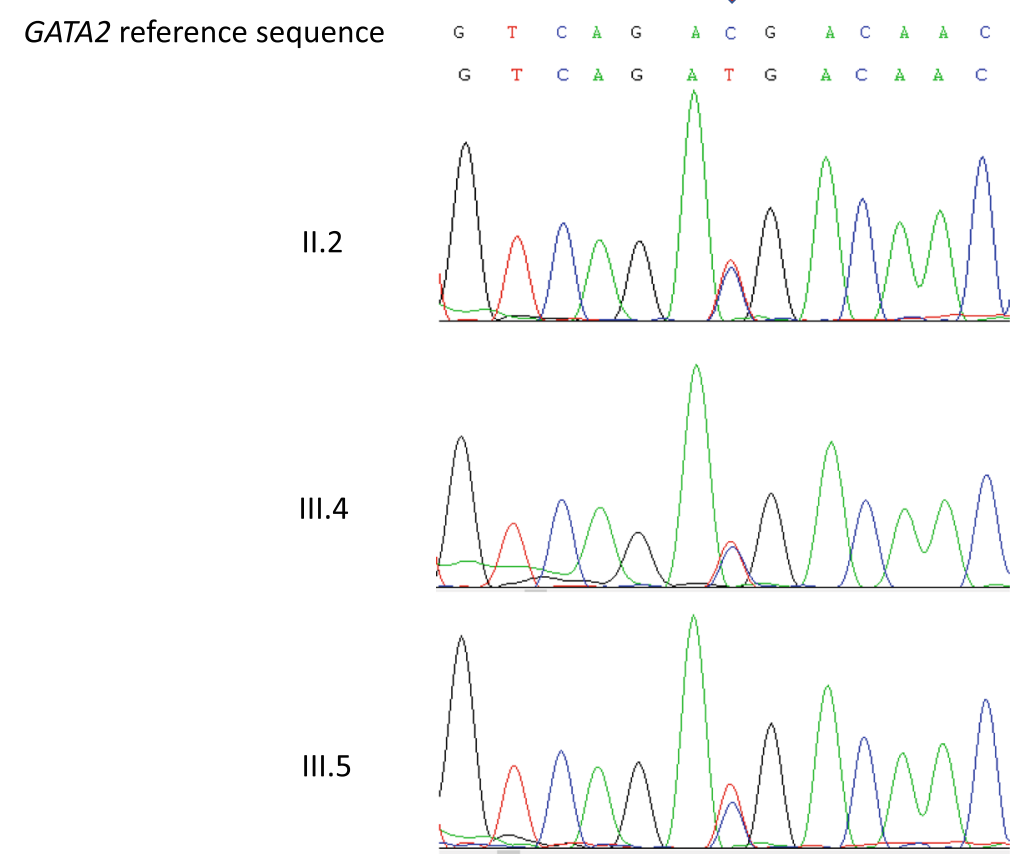

Fig. 3 GATA2 direct Sanger sequencing Electropherogram of GATA2 sequencing showing the mutation c.1061 C> T; p.T354 M at the second zinc finger domain in the proband and both sons

Table 1 Principal clinical features of GATA2 deficiency described previously and presented in this case report

\begin{tabular}{|c|c|c|c|}
\hline Features $^{a}$ & Details $^{a}$ & Approximate frequency $^{a}$ & Case report presentation \\
\hline MDS/AML & $\begin{array}{l}\text { Early-onset, familial history, bone } \\
\text { marrow fibrosis, aggressive disease, } \\
\text { associated with secondary mutations }\end{array}$ & $\begin{array}{l}30-50 \% \text { at presentation, } 30 \text { years- old } \\
\text { median onset, } 90 \% \text { lifetime risk }\end{array}$ & Yes \\
\hline Warts, severe Viral infection & HPV all serotypes, herpesviruses & $\begin{array}{l}\text { 60-70\% at presentation, } 10-20 \% \\
\text { disseminated CMV, VZV and EBV }\end{array}$ & No \\
\hline $\begin{array}{l}\text { Pulmonary alveolar proteinosis } \\
\text { or decreased lung function }\end{array}$ & $\begin{array}{l}\text { PAP (GM-CSF antibody negative), } \\
\text { pulmonary arterial hypertension, } \\
\text { loss of volume or diffusion, } \\
\text { pneumonia }\end{array}$ & $\begin{array}{l}\text { 18\% proven PAP } \\
10 \% \text { PAH } \\
50 \% \text { abnormal PFT } \\
14 \% \text { pneumonia }\end{array}$ & $\begin{array}{l}\text { Yes (he had only } \\
\text { pulmonary infiltrate) }\end{array}$ \\
\hline Mycobacterial or fungal infection & $\begin{array}{l}\text { NTM (MAC and others) aspergillosis, } \\
\text { histoplasmosis }\end{array}$ & $\begin{array}{l}20-50 \% \text { NTM } 16 \% \text { aspergillosis, } \\
9 \% \text { histoplasmosis }\end{array}$ & Yes \\
\hline $\begin{array}{l}\text { Recurrent upper respiratory tract } \\
\text { infection }\end{array}$ & Otitis, sinusitis & $10-20 \%$ & Yes \\
\hline Autoimmune manifestations & $\begin{array}{l}\text { Panniculitis, arthritis, lupus-like, } \\
\text { hypothyroidism, hepatitis/PBC }\end{array}$ & $\begin{array}{l}30 \% \text { panniculitis, arthritis in up to } \\
50 \% \text { overall }\end{array}$ & Yes \\
\hline Solid malignancy & $\begin{array}{l}\text { HPV and EBV- mesenchymal } \\
\text { related, breast, prostate and } \\
\text { kidney cancer, metastatic } \\
\text { melanoma }\end{array}$ & $\begin{array}{l}20-35 \% \text { intra-epithelial neoplasia, } \\
22 \% \text { of women with > } 35 \text { years } \\
\text { breast cancer, other skin cancer 10\% }\end{array}$ & No \\
\hline Lymphedema & Childhood or adolescence & $11-20 \%$ & No \\
\hline Thrombosis & DVT, PE, Catheter-related & $25 \%$ risk overall & Yes \\
\hline Deafness & Neurosensorial & $20 \%$ abnormal audiograms & No \\
\hline
\end{tabular}

MDS myelodysplastic syndrome, $A M L$ acute myeloid leukaemia, HPV human papilloma virus, CMV cytomegalovirus, EBV Epstein- Barr virus, VZV varicella zoster virus, PAP pulmonary alveolar proteinosis, GM-CSF granulocyte-macrophage colony-stimulating factor, PAH pulmonary arterial hypertension, PFT pulmonary function tests, NTM nontuberculous mycobacteria, MAC Mycobacterium avium complex, PBC primary biliary cirrhosis, DVT deep vein thrombosis, PE pulmonary embolism. ${ }^{a}$ According to Collin et al., 2015 
and dermatological manifestations with hypothyroidism, panniculitis/erythema nodosum, arthritis and vasculitis. MonoMAC-associated MDS is usually hypocellular, shows atypical megakaryocytes, and fibrosis [8]. The 2016 revision of the World Health Organization classification for myeloid neoplasms has incorporated a subgroup of cases associated with germline mutations, that includes GATA2 [9]. GATA2mut is associated with MonoMAC syndrome despite of variable GATA2 expression and initial presentation spanning from early childhood to late adulthood, with a median age of presentation of 32 years with viral, mycobacterial or fungal infections [6]. The ubiquitous influence of NTM and other infections, accompanied by co-occurrence of monocytopenia, lymphopenia, neoplasia and a vast possibility of symptoms make the initial diagnosis of MonoMAC syndrome difficult for physicians. Clinical suspicion of MonoMAC syndrome is critical to make an early genetic diagnosis and to direct an appropriate management. Other gene mutations, such as mutations in $I L 12 R$ or $I F N \gamma R$ receptors or STAT1, are also important for differential diagnosis, however, CD4+, T cell and monocyte numbers are often normal in these conditions [1]. Genetic counselling should be offered to at-risk individuals [10]. The proband's father died prematurely from a coronary artery disease (CAD). Because GATA2 has been functionally involved in the pathophysiology of thrombosis and CAD [11], we hypothesized that GATA2 mut would be present in the first generation of this patient's family, but we didn't have biological material to test him. In healthy carriers of GATA2 mutations, antimicrobial prophylaxis with azithromycin and immunization against human papilloma virus (HPV) are suggested as follow-up treatments [10]. Other recommendations at diagnosis are screening for HPV infection and HPV-related cervical, head and neck and anogenital cancer as well as baseline pulmonary evaluation [10]. It is also important to educate patients and physicians about the increased risk of opportunistic infections, especially NTM. Vigilant BM monitoring, immunoglobulin replacement when low or with recurrent infections, screening for congenital deafness and avoidance of ototoxic drugs are all recommended [10]. Even though characterized as autosomal dominant inheritance, GATA2 mutations are germline heterozygous and might have incomplete penetrance [12]. Allogenic HSCT has been curative for haematopoietic disease in some cases using nonmyeloablative conditioning regimens [13]. Among individuals with GATA2 deficiency progressing to MDS/AML, acquired secondary mutations in the ASXL1 that encoding chromatin-binding protein ASXL1 are detected in approximately $30 \%$ of cases, despite being negative in our patient (data not shown) [14]. The prognosis after MDS/AML diagnosis appears to be poor, with the best outcomes reported among individuals undergoing allogeneic HSCT in the early stages of the disease, with an overall survival rate of $57 \%$ at 36 months [4]. In conclusion, we presented a patient with long history of NTM infection, MDS, monocytopenia, autoimmune and thrombotic phenomena, hypothyroidism and carrying a GATA mutation. The delay in diagnosis of MonoMAC syndrome is explained by the diversity of clinical features and lack of medical knowledge by the period of disease presentation. With this report, we hope to call attention to the importance of early diagnosis of this immunodeficiency syndrome. Genetic counselling, clinical management, and HSCT in early disease stages can be safely offered.

\section{Additional file}

Additional file 1: Table S1. GATA2 and ASXL1 genes conditions, oligoprimers and sequences and PCR conditions for Sanger Sequencing. (DOCX $18 \mathrm{~kb}$ )

\section{Abbreviations}

AML: Acute myeloid leukaemia; BM: Bone marrow; CAD: Coronary artery disease; HPV: Human papilloma virus; HSCT: Haematopoietic stem cell transplant; IFN- $\gamma$ : Interferon- $\gamma$; IL-12: Interleukin-12; MDS: Myelodysplastic syndrome; NK: Natural killer; NTM: Disseminated non-tuberculosis mycobacterium; RAEB2: Anaemia with excess blasts type 2; WBC: White blood cell

\begin{abstract}
Acknowledgments
The authors thank the patient relatives who made samples available, provided written informed consent and helped with information, as well as the many physicians who provided patient data and clinical details in the course of treatment, especially Amanda Marques and Mariana Mazzi; the pathologists Alessandra Nascimento, Sergio Romano and Roberto Arcuri, who provided histopathological pictures; and the researcher Elizabeth P. Sampaio, who kindly revised this manuscript.
\end{abstract}

\section{Funding}

This work was partially supported by Fundação de Amparo a Pesquisa de Estado do Rio de Janeiro-FAPERJ, [grant\#218785/2015 to D.A.M.C.]; Fundação de Amparo a Pesquisa de Estado de São Paulo-FAPESP [grants \# 2013/08135-2 and 2014/ 26379-9 to R.T.C]; M.S.P.O. and R.M.Z.O. are supported by Conselho Nacional de Desenvolvimento Científico e Tecnológico- CNPq [\#301594/2015-5 and \# 394976/ 2013-0, respectively]. This study was financed in part by the Coordenação de Aperfeiçoamento de Pessoal de Nível Superior - Brasil (CAPES) - Finance Code 001

\section{Availability of data and materials \\ The clinical documentation is available to the corresponding author on reasonable request.}

\section{Authors' contributions}

DPMA., designed the study, collected and analysed clinical data; IFV. and LKMSR. assisted the patient and provided the samples for genetic studies; DPMA., FGA., FVSB. and GB. performed genetic tests; MSPO. and RTC. supervised the study and reviewed the manuscript; DAMC. and RMZO provided funding and revised the manuscript. All authors contributed significantly to the work, have seen and approved the manuscript and its submission.

\section{Ethics approval and consent to participate}

Informed consent was obtained from the case in accordance with the Declaration of Helsinki and ethics was approved by the Ethics and Research Committee of Evandro Chagas Institute for Clinical Research (reference number CAAE \#64574417.0.0000.5262). 


\section{Consent for publication}

Written informed consent for publication of the patient's clinical information and molecular data were obtained from the patient's family (mother, wife and sons, brothers and nefews), who also provided authorization to publish the family pedigree. All this information is available for the journal.

\section{Competing interests}

The authors declare that they have no competing interests.

\section{Publisher's Note}

Springer Nature remains neutral with regard to jurisdictional claims in published maps and institutional affiliations.

\section{Author details}

'Division of Hematology, Evandro Chagas National Institute of Infectology, Oswaldo Cruz Foundation, Rio de Janeiro, Brazil. ²Pediatric Hematology-Oncology Program, 6thfloor, Research Center, Instituto Nacional de Câncer-INCa, Rua André Cavalcanti, 37, Rio de Janeiro Zip code: 20231050, Brazil. ${ }^{3}$ Department of Internal Medicine, Ribeirão Preto School of Medicine, University of São Paulo, Ribeirão Preto, Brazil. ${ }^{4}$ Infectious Diseases Department, Hospital dos Servidores do Estado, Rio de Janeiro, Brazil. ${ }^{5}$ Division of Hematology, Oncologia D'Or, Rio de Janeiro, Brazil. 'Laboratory on Thymus Research, Oswaldo Cruz Institute, Oswaldo Cruz Foundation, Rio de Janeiro, Brazil. ${ }^{7}$ Institute of Science and Technology on Neuroimmunomodulation (INCT-NIM), Oswaldo Cruz Institute, Oswaldo Cruz Foundation, Rio de Janeiro, RJ, Brazil. ' ${ }^{8}$ Laboratory of Mycology, Evandro Chagas National Institute of Infectology, Oswaldo Cruz Foundation, Rio de Janeiro, Brazil.

Received: 23 August 2018 Accepted: 3 April 2019

Published online: 29 April 2019

\section{References}

1. Wu U-I, Holland SM. Host susceptibility to non-tuberculous mycobacterial infections. Lancet Infect Dis. 2015:15:968-80.

2. Collin M, Dickinson R, Bigley V. Haematopoietic and immune defects associated with GATA2 mutation. Br J Haematol. 2015;169:173-87.

3. Dickinson RE, Milne P, Jardine L, Zandi S, Swierczek SI, McGovern N, et al. The evolution of cellular deficiency in GATA2 mutation. Blood. 2014; 123:863-74.

4. Spinner MA, Sanchez LA, Hsu AP, Shaw PA, Zerbe CS, Calvo KR, et al. GATA2 deficiency: a protean disorder of hematopoiesis, lymphatics, and immunity. Blood. 2014;123:809-21.

5. Hsu AP, Sampaio EP, Khan J, Calvo KR, Lemieux JE, Patel SY, et al. Mutations in GATA2 are associated with the autosomal dominant and sporadic monocytopenia and mycobacterial infection (MonoMAC) syndrome. Blood. 2011;118:2653-5.

6. Vinh DC, Patel SY, Uzel G, Anderson VL, Freeman AF, Olivier KN, et al. Autosomal dominant and sporadic monocytopenia with susceptibility to mycobacteria, fungi, papillomaviruses, and myelodysplasia. Blood. 2010;115: 1519-29.

7. Hirabayashi S, Wlodarski MW, Kozyra E, Niemeyer CM. Heterogeneity of GATA2-related myeloid neoplasms. Int J Hematol. 2017;106:175-82.

8. Calvo KR, Vinh DC, Maric I, Wang W, Noel P, Stetler-Stevenson M, et al. Myelodysplasia in autosomal dominant and sporadic monocytopenia immunodeficiency syndrome: diagnostic features and clinical implications. Haematologica. 2011:96:1221-5.

9. Arber DA, Orazi A, Hasserjian R, Thiele J, Borowitz MJ, Le Beau MM, et al. The 2016 revision to the World Health Organization classification of myeloid neoplasms and acute leukemia. Blood. 2016;127:2391-405.

10. The University of Chicago Hematopoietic Malignancies Cancer Risk Team. How I diagnose and manage individuals at risk for inherited myeloid malignancies. Blood. 2016;128:1800-13.

11. Connelly JJ, Wang T, Cox JE, Haynes C, Wang L, Shah SH, et al. GATA2 is associated with familial early-onset coronary artery disease. PLoS Genet. 2006;2:e139

12. Donadieu J, Lamant M, Fieschi C, de Fontbrune FS, Caye A, Ouachee M, et al. Natural history of GATA2 deficiency in a survey of 79 French and Belgian patients. Haematologica. 2018;103:1278-87.
13. Cuellar-Rodriguez J, Gea-Banacloche J, Freeman AF, Hsu AP, Zerbe CS, Calvo $\mathrm{KR}$, et al. Successful allogeneic hematopoietic stem cell transplantation for GATA2 deficiency. Blood. 2011;118:3715-20.

14. Bodor C, Renneville A, Smith M, Charazac A, labal S, Etancelin P, et al. Germline GATA2 p.THR354MET mutation in familial myelodysplastic syndrome with acquired monosomy 7 and ASXL1 mutation demonstrating rapid onset and poor survival. Haematologica. 2012;97:890-4.

\section{Ready to submit your research? Choose BMC and benefit from:}

- fast, convenient online submission

- thorough peer review by experienced researchers in your field

- rapid publication on acceptance

- support for research data, including large and complex data types

- gold Open Access which fosters wider collaboration and increased citations

- maximum visibility for your research: over $100 \mathrm{M}$ website views per year

At BMC, research is always in progress.

Learn more biomedcentral.com/submissions 